\title{
The dental recruitment crisis
}

\author{
David Payne investigates the current state of UK dental recruitment and \\ finds out how this is affecting employers and employees.
}

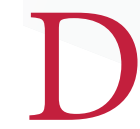
ental recruitment is in the doldrums, a crisis blamed by many on the looming Brexit deadline, poor workforce planning, low morale, contract obligations, even rising student debt. British Dental Association (BDA) figures published in February indicate $68 \%$ of NHS practices in England struggled to fill vacant posts, an $18 \%$ rise on the 2016 figure. ${ }^{1}$

In January councillors in Plymouth, Devon, urged the city's public health director Ruth Harrell to lobby Public Health England about dental recruitment following claims that some patients were facing a six-hour round trip to Seaton, almost 70 miles away.

A previous BDA survey, published in October 2017, showed almost 58\% of NHS dentists were planning to leave the health service in the next five years. Almost one in ten of those aged under 35 said they planned to quit dentistry altogether, with a similar number hoping to move overseas.

An analysis of General Dental Council (GDC) registration data between 2006 and 2016, published in the BDJ in January, showed that overall almost $40 \%$ of new entrants currently come from overseas and more than a quarter are able to do so because their dental qualifications are mutually recognised. ${ }^{2}$ Dentists from European Economic Area (EEA) countries clocked up the lowest periods on the register, an average of just 8.1 years for men, and 6.5 years for women.

The author of the study Dr Paul Batchelor suggested 'possible changing culture within Britain and its attitude to immigration' could be a contributing factor, adding: 'The lack of clarity that the Government has provided on EEA graduates' future possible working arrangements is worrying.'

A BBC News analysis of 2,500 dental practices in England, published in September 2017, found that $48 \%$ were not accepting new adult NHS patients, and $40 \%$ were turning new child patients away. ${ }^{3}$

The picture certainly looks bleak, but what does it feel like on the ground for job seeking dentists, practice owners and associates, particularly those working in regions worst affected?

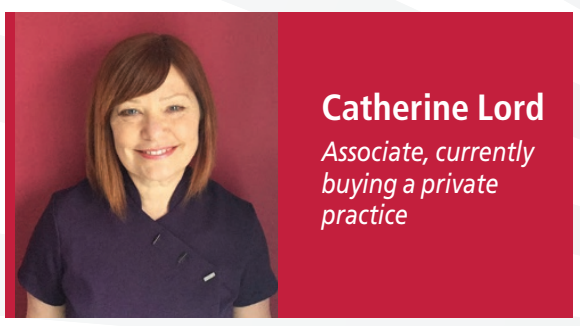

Catherine graduated in 1988 and worked as an associate in a large NHS practice in central Lincoln for 27 years, an area often cited by recruitment agencies as one struggling to recruit and retain staff. She is currently buying a private practice in Welton, a village north of the city.

How has the dental recruitment crisis affected you personally?

The owner of my current practice is planning to sell up and retire, so I'm moving on. The practice I'm buying has two surgeries but it will be just me to start with. It feels like the right time.

There's quite a shortage of dentists in Lincolnshire. I'm not sure why. It's an undiscovered secret. I'm hoping to get an associate at some point but I'm not worrying about that at the moment. I think I can manage on my own.

I'd like to retire in around ten years and pass it on to someone else. I go to local BDA meetings and in the last couple of months there seems to be some 'young blood' coming through, dentists from this area who have decided to move back. To me that's quite hopeful.

\section{What needs to change?}

When I first started in the NHS 30 years ago it was a nice environment. But it's hard right now. Money is the big thing, much more target-driven than when I qualified. One of the reasons I'm moving away from the health service is because I am fed up of the targets. I was hitting them, but I can't work any faster. The pressure to deliver UDAs since 2006 puts a strain on the relationships between associates and practice owners, who are themselves under pressure to meet targets. It's not a nice 
way to work, particularly if you are newly qualified and still finding your way. The system is fundamentally flawed. What gets measured gets done and you're not rewarded for all the other things. Moving back to a fee-per-item might be more expensive, but it is fairer on patients.

\section{Would you recommend dentistry to your children?}

None of my four children have shown an interest, but if they did I would say it's changed since I qualified. I wouldn't stop them but I would be wary for them.

\section{How do you feel about your own future?} I hope to have more time with patients. That's the one thing I haven't enjoyed. You really do feel they are in and out. I've always tried to do my best.

I'm coming quite late to running my own practice and might need to do further courses. My husband was a lawyer and had a complete career change. He makes furniture. It's not lucrative but he's much happier. We've bought the practice together and he will be my practice manager. He's done all the admin and compliance stuff, which he's great at after working in the law.

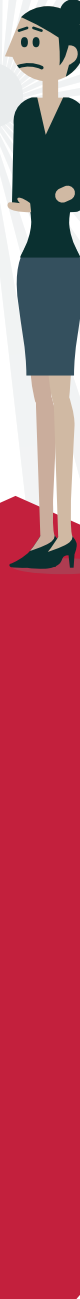

What will dentistry be like in the future? I see a situation where you have a dentist employing four or five therapists because it's cheaper. Then dentists will have to specialise more and you will need more therapists.

I haven't really noticed any Brexit effect yet, although a friend who runs a practice in Lincoln employs EU nationals and she has struggled to keep them. I don't know if that's to do with the Brexit vote. The practice I just left is trying to replace me, and one candidate is from the Sudan. Maybe dentists might come from further afield in the future?

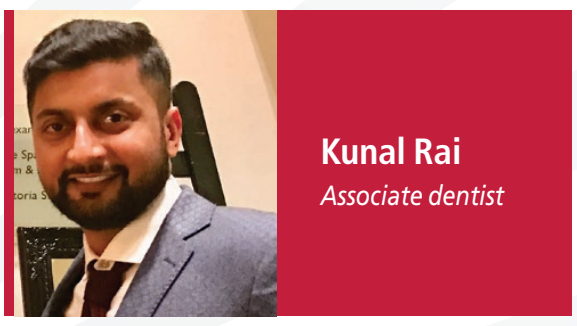

Kunal qualified in 2015 and worked in Bridlington, East Yorkshire, for a year, before joining a BUPA practice with NHS patients in Pontefract. He also works at a BUPA practice in Hull once a month, seeing private patients mostly.

How has the dental recruitment crisis affected you personally?

When I joined the Pontefract practice in January 2017 there were three of us, but at one point I was the only dentist for six months. It was stressful but it did keep me busy. At the end of the day you have UDA targets to meet.

\section{What needs to change?}

There is too much litigation and regulation. You are always worrying about doing the right thing. You never know if a patient will turn round and say you did something wrong. You can spend more time doing paperwork than seeing patients. Because of UDA targets you are not able to give the best service that you can. It's about profit.
Would you recommend dentistry to your children?

My daughter has just turned one but if asked by older children I would say it depends on what happens with the NHS around the UDA scheme. My hope is that it may come back to being an attractive job, not just for the money but for professional satisfaction too. So that's a 'yes and no'.

How do you feel about your own future? I love the variety and don't regret choosing dentistry over medicine as my second degree. My first was in computer science and I worked in IT for four years. The length of the training for medicine and dentistry put me off at first. My dad is a surgeon and urologist and before he retired I watched him doing more paperwork and not being able to prescribe medications on cost grounds. I work privately in Hull once a month and I do feel there that I can give what I want more.

What will dentistry look like in the future? I'm doing a diploma in restorative dentistry at the moment. We'll still need dentists but things will become more technology led, using artificial intelligence etc.

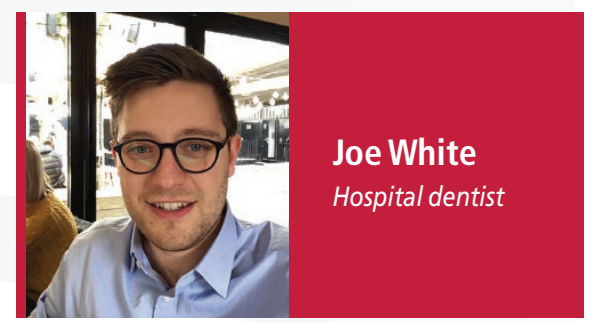

Joe's degree at Sheffield (he graduated in 2015) included an extra year in research. He did his vocational training in Rochester, followed by a maxillofacial job at Wythenshawe hospital for a year, and then six months in restorative dentistry at Manchester Dental Hospital. He recently started a six-month position at Blackburn Hospital and has applied for orthodontics training.

\section{How has the dental recruitment crisis affected you personally?}

I get the impression that resources in secondary care are more strained than they used to be. The culture in primary care is that everything is a risk. My limited experience of general practice suggests that you can see the business case behind some referrals to secondary care, a worry that they might lose 
money by treating them and wanting the hospital to be a route out.

\section{What needs to change?}

I've not worked under the UDA system so it's difficult for me to comment. Some really noble dentists are doing great jobs with limited resources. The demand for root canal treatment, for example, is just obscene, and it's the thing dentists don't get paid for. The amount that's needed can't be provided in primary care. The technology within dentistry is advancing at great speed and I think we may soon reach a stage where it becomes too difficult or costly for GDPs to adopt and practise all the the new skills available across all specialities. The profession is being pushed towards facial aesthetics. Everyone wants to put implants in but there's very little hype about getting good at doing root canal treatment.

\section{Would you recommend dentistry to your children?}

I don't have any, but my answer would depend on their reasons for wanting to pursue it. You really have to question why you want to do dentistry especially at the moment when it is going through so many changes in every possible dimension.

I did it because I liked the idea of using science to help people, I didn't fancy the lifestyle of medicine, and it will always be a secure career. I think the trickiest thing for me has been dealing with the stigma of dentistry, the business side of things, and the amount of dental phobia.
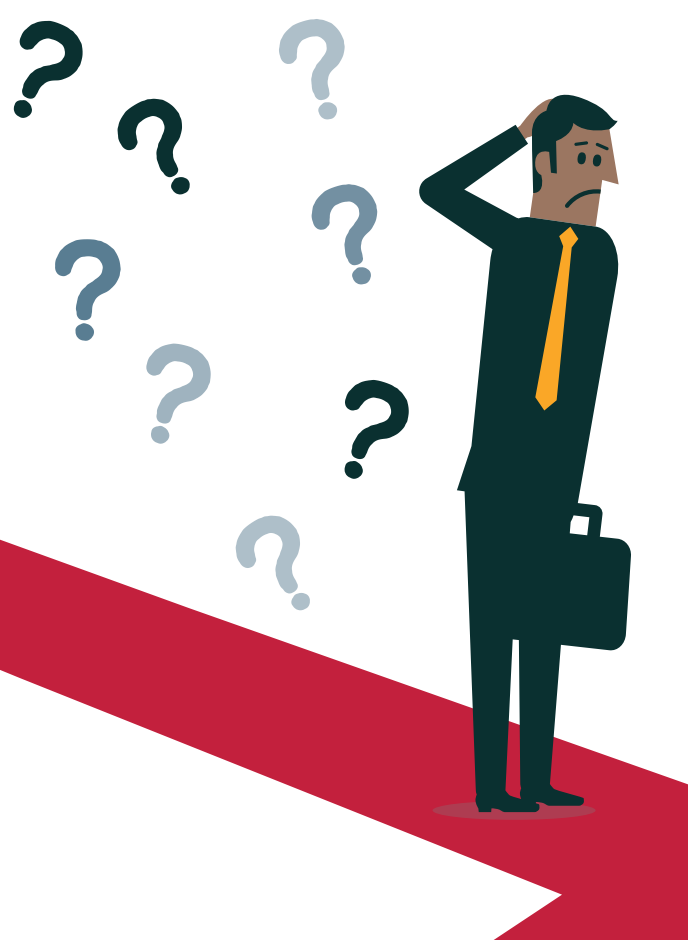

It's a very public facing profession, you need really good soft skills, and that can lead to some soul-searching when you first graduate as you deal with some patients who just don't want to see you, and may even distrust you and not respect the (limited) expertise you have. I found this really tricky to cope with after the amount of time and money I spent investing in myself.

How do you feel about your own future? I'm enjoying my training but postgraduate training is a little bit messed up. It's quite difficult to get the experience that you want. You need to demand power there and that's in hospitals, where it can't be fulfilled by medically qualified doctors. With orthodontics, for example, the courses are NHS but a large majority will end up in private practice, so there's a concern that the NHS isn't getting a return on its investment.

\section{What will dentistry be like in the future?} The regenerative capacity of dentistry will be the biggest change, getting better at actually saving teeth rather than replacing them, using the body's capacity to grow teeth to some degree.

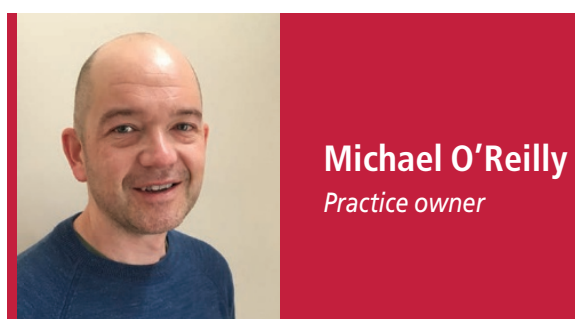

Michael qualified from Manchester in 1995 and moved into general practice five years later after working in Lancaster and Birmingham. He bought into his current two-surgery practice in Prestbury, Cheshire, in 2005. It treats predominantly NHS patients.

\section{How has the dental recruitment crisis} affected you personally?

I'm not directly involved in recruitment. When my last dentist left eight years ago I employed an associate who is now a partner. My practice workforce is very stable. It's in an affluent area near Macclesfield. Manchester and Liverpool are close by. It's a nice place to work.

You used to be able to open a practice almost anywhere as a young dentist and people would turn up for treatment. You can't do that nowadays because of the investment required, the contract, regulatory bodies, the CQC. You'll have accrued student debts. Corporates are drawing in dentists and not paying them particularly well.

\section{What needs to change?}

The UDA system is flawed. Dentists get paid the same amount for one filling as they would for ten. It's very difficult to make it work. There needs to be a greater focus on preventing dental disease before it starts, but the UDA system doesn't pay anything for that. It's not funded in schools either.

\section{Would you recommend dentistry to your children?}

My gut feeling right now is no. The oldest of my three boys is at GCSE stage and is starting to be interested in science. I've really enjoyed dentistry, but the amount of regulation and the set-up costs for a practice would put me off. Also the fear of litigation is rife in dentistry. It's not a stable career choice.

\section{How do you feel about your own future?} I'm sticking with the NHS for now. I'll review things when the new contract comes out in the next couple of years. It's being prototyped but we're not getting any communication about what's involved.

\section{What will dentistry be like in the future?}

The government has this image of the dentists being at the top of the pile, doing the more complicated work. But it has an agenda. It wants dentistry on the cheap. I can see why it wants to cut costs. The NHS is stretched. So therapists are being trained to do things on the cheap. But they don't do 5-6 years at university. And patients want continuity of care. They like seeing me. I know them.

Orthodontics are further down the line and the government is trying to remove a lot from the NHS and reducing contract values and putting contracts up to tender. A colleague of mine recently bought an NHS orthodontics practice for quite a lot of money and is now having to retender for her own contract.

I think that's the way general practice will go in the next 5-10 years. You can't do that with a healthcare system. 


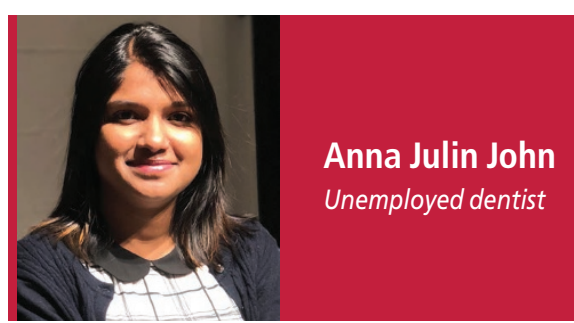

Anna qualified from the University of Kerala in 2015 and moved to the UK the following year when her husband started working at St George's Hospital in Tooting, south London, as a junior doctor. She returned to India to have her daughter, and came back to the UK in December 2017.

\section{How has the dental recruitment crisis affected you personally?}

My degree course in India lasted fourand-a-half years and I then undertook 12 months of clinical dentistry there for my foundation training. Since coming to the UK two years ago I have had a few interviews and phone conversations about vocational training posts, but when I say I have one year's experience they don't call me back. Dentistry seems to be more interested in experienced dentists.

\section{What needs to change?}

There are too few opportunities for vocational training, which for dentists like me with just one year's experience is a challenge. I hear anecdotally that the number of mentors is going down, particularly in London, and that there isn't the funding to support them. I'm willing to relocate for my career but we can't move at the moment as my husband is still a trainee. London is quite expensive.

\section{Would you recommend dentistry to your children?}

If my daughter did become interested in dentistry or medicine when she's older I would support her, but personally I'd like her to go into another area. My husband is working very hard as a junior doctor. He just got home after 11 hours.

How do you feel about your own future? It's disheartening right now, but I'm very positive about my future in the UK. If I can get my vocational training sorted, and then a performer number with the NHS, it will get much easier for us. Hopefully in five or ten years' time things will be quite stable for us. I'm attending dentistry-related classes to keep up with CPD requirements. Even without a job it's important for me to keep my skills updated.

What will dentistry be like in the future? It's hard for me to say right now as I don't have a job. I just need to get the experience I need.

1. British Dental Association. NHS dentistry facing recruitment crisis. 4 February 2018. Available at: https://bda. org/news-centre/press-releases/nhs-dentistry-facing-recruitment-crisis (accessed March 2018).

2. Batchelor P. Registration and retention of dentists on the General Dental Council register between 2006 and 2016. Br Dent J 2018; 224: 105-109.

3. Rhodes D. 'We couldn't see an NHS dentist so we pulled out our own teeth' BBC News 6 September 2017. Available at: http://www.bbc.co.uk/news/uk-england-41113507 (accessed March 2018).

For the latest dental jobs, visit BDJ Jobs: https://www.bdjjobs.com/. BDJ Jobs can provide guides to writing job adverts and set up employer profiles so that you get the most from its services. 